\title{
State-Dependent Processing of Sensory Stimuli by Thalamic Reticular Neurons
}

\author{
Jed A. Hartings, Simona Temereanca, and Daniel J. Simons \\ Department of Neurobiology, University of Pittsburgh School of Medicine, Pittsburgh, Pennsylvania 15261
}

\begin{abstract}
Inhibitory neurons of the thalamic reticular (RT) nucleus fire in two activity modes, burst and tonic, depending on an animal's behavioral state. In tonic mode, depolarized RT cells fire single action potentials continuously, whereas burst firing consists of grouped discharges separated by periods of quiescence. To determine how these firing modes affect sensory-evoked RT responses, single-unit responses to controlled whisker deflections were analyzed according to the burst versus tonic mode of spontaneous activity (SA) preceding the response. After burst mode activity (i.e., either quiescence or spontaneous bursts), responses exhibited a slow $\sim 15 \mathrm{msec}$ rise to peak firing rates followed by a $\sim 35 \mathrm{msec}$ decay. Interspike intervals within the response exhibited accelerando-decelerando patterns similar to those of spontaneous bursts. After tonic mode activity (i.e., single spikes), responses had a nearly instantaneous $\sim 1.5 \mathrm{msec}$ rise-topeak followed by a $\sim 40 \mathrm{msec}$ decay, with large spike counts ( 5.2 spikes per stimulus) similar to those evoked in burst mode ( 6.2 spikes per stimulus). Interspike intervals were longer in tonic mode and exhibited a decelerando pattern. Initial evoked spikes, however, had shorter latencies and greater synchrony, contributing to the rapid onset of tonic population response. Shifts from quiescent (presumed burst mode) to tonic SA could be induced by either previous whisker deflections or iontophoretic application of NMDA; both manipulations effected appropriate shifts from burst to tonic response spike patterns. In awake animals, burst and tonic firing in RT, as in thalamocortical relay nuclei, may reflect sensory processing strategies appropriate for different behavioral and attentional states.
\end{abstract}

Key words: TRN; inhibition; T-type calcium current; whisker; burst; tonic; vigilance

Thalamic neurons possess intrinsic biophysical properties the expression of which varies with an animal's behavioral state and thus may underlie state-dependent or attentional differences in an animal's perception of external stimuli. In particular, thalamic reticular (RT) neurons can discharge action potentials in two activity modes (Mukhametov et al., 1970; Domich et al., 1986; McCormick and Prince, 1986; Spreafico et al., 1988). During attentive wakefulness, RT neurons exhibit continuous "single spike" activity, a condition known as tonic mode firing. During states of drowsiness and synchronized sleep, RT neurons transition to burst mode firing, characterized by intermittent grouped discharges and intervening periods of quiescence (Mukhametov et al., 1970; Steriade et al., 1986). Because RT neurons densely innervate dorsal thalamic nuclei and receive inputs from topographically aligned thalamocortical and corticothalamic cells (Scheibel and Scheibel, 1966; Pinault and Deschenes, 1998), their different firing modes may effect state-dependent processing in respective thalamocortical loops (Fanselow and Nicolelis, 1999; Nicolelis and Fanselow, 2002).

RT spike bursts are generated by low-threshold T-type $\mathrm{Ca}^{2+}$ channels $\left(I_{\mathrm{T}}\right)$ which produce broad, low-threshold spikes (LTS). An LTS can support up to 12 fast $\mathrm{Na}^{+}$spikes, which exhibit a characteristic accelerando-decelerando pattern in firing frequency (Mulle et al., 1986; Huguenard and Prince, 1992; Contreras et al., 1993). Expression of $I_{\mathrm{T}}$, however, depends on its state

Received Sept. 26, 2002; revised March 17, 2003; accepted April 7, 2003

This work was supported by National Institute of Mental Health Grant MH61372.

Correspondence should be addressed to Jed A. Hartings, Division of Neurosciences, Walter Reed Army Institute of Research, 503 Robert Grant Avenue, Silver Spring, MD 20910. E-mail: jed.hartings@amedd.army.mil.

Copyright $\odot 2003$ Society for Neuroscience $\quad$ 0270-6474/03/235264-08\$15.00/0 of inactivation. At hyperpolarized potentials, as occur during early stages of sleep, $I_{\mathrm{T}}$ becomes deinactivated and can produce an LTS during subsequent depolarization. At sufficiently depolarized potentials, as occur more frequently during wakeful activity, inactivation prevents $I_{\mathrm{T}}$ conductance.

It is presumed that the burst and tonic activity modes in RT neurons have distinct consequences for information processing in thalamocortical circuits during different behavioral states (Crick, 1984; Nicolelis and Fanselow 2002). However, previous studies of somatosensory responses in RT have been performed with little regard to the firing modes of its neurons. In these studies, RT neurons in the rat responded to whisker deflections with up to 13 spikes per stimulus, as compared with an average of 1-2 spikes in their thalamocortical input neurons (Pollin and Rokyta, 1982; Shosaku, 1985; Hartings et al., 2000). In some instances, such as the occurrence of evoked repetitive bursting, it is apparent that these large amplitude responses are mediated by $I_{\mathrm{T}}$ (Shosaku 1985; Sumitomo and Iwama 1987). Whether large magnitude responses, as those mediated by $I_{\mathrm{T}}$, occur only during burst mode firing is unknown.

Here we analyze responses of RT neurons to whisker deflections according to the patterns of prestimulus spontaneous firing. We find that sensory-evoked responses are robust and of long duration when evoked during spontaneous firing characteristic of either burst or tonic mode activity. However, the temporal patterns of evoked activity differ for these spontaneous activity (SA) modes. Results suggest that in burst mode $I_{\mathrm{T}}$ functions as a mechanism of high synaptic gain in sensory processing. Because the availability of this conductance determines the firing mode of a cell, $I_{\mathrm{T}}$ likely contributes to state- and behavior-dependent differences in thalamic sensory processing. 


\section{Materials and Methods}

Animal surgery and preparation. All procedures were approved by the University of Pittsburgh Animal Care and Use Committee and conform to guidelines set forth in the Guide for the Care and Use of Laboratory Animals. Adult female Sprague Dawley rats weighing 250-300 gm were prepared for electrophysiological study using methods described previously in detail (Simons and Carvell, 1989; Hartings et al., 2000). Halothane anesthesia was used during surgical procedures. A steel post was secured to the skull over the left parietal cortex with dental acrylic to hold the animal's head, and a craniectomy was made at stereotaxic coordinates overlying the somatosensory sector of RT in the right hemisphere (1.53.5 posterior, 2.5-4.5 lateral to bregma) (Paxinos and Watson, 1982; Shosaku et al., 1984). After surgery halothane was discontinued, and during recording sessions animals were maintained in a lightly narcotized state (Simons and Carvell, 1989) by a steady infusion of fentanyl, an opiate receptor agonist (Sublimaze, Jansen Pharmaceuticals) $(\sim 10$ $\left.\mathrm{mg} \cdot \mathrm{kg}^{-1} \cdot \mathrm{h}^{-1}\right)$. To prevent spontaneous movements of the whiskers, which would preclude the use of controlled whisker deflections (see below), animals were immobilized by pancuronium bromide (1.6 $\mathrm{mg} \cdot \mathrm{kg}^{-1} \cdot \mathrm{h}^{-1}$, i.v.), artificially respired through a tracheal cannula, and warmed by a servo-controlled heating blanket. Paralysis and artificial respiration are not associated with physiologic stress responses in chronically maintained rats (Dworkin and Dworkin, 1995). Rats was inspired at $85-100$ breaths per minute using a pressure-controlled respirator that was adjusted to deliver a 50/50\% mixture of $\mathrm{N}_{2}$ and $\mathrm{O}_{2}$ at 11-15 $\mathrm{cm} \mathrm{H}_{2} \mathrm{O}$ monitored at the tracheal cannula. The animal's condition was assessed by reference to electroencephalogram, femoral arterial blood pressure, heart rate, tracheal airway pressure waveform, and pupillary reflexes. A computer program sounded an alarm if mean arterial pressure $(110-130 \mathrm{mmHg})$ or heart rate $(400-450$ beats per minute) exceeded normative values (Harkness and Wagner, 1989) or if the airway pressure waveform changed shape, indicating tracheal blockage. Experiments were terminated if any of the physiologic parameters could not be maintained. At the end of recording sessions animals were deeply anesthetized with sodium pentobarbital (Nembutal, $100 \mathrm{mg} / \mathrm{kg}$, i.v.) and perfused transcardially. Brains were sectioned in the coronal plane and processed for cytochrome oxidase histochemistry or stained with thionin, or both, to confirm the location of electrode tracks through RT.

Electrophysiological recordings and microiontophoresis. Initial mapping and single-unit recordings of RT neurons were made with $10 \mathrm{M} \Omega$ stainless steel microelectrodes (Frederick Haer, Brunswick, ME) as reported in Hartings et al. (2000). For simultaneous recording and microiontophoresis, three-barrel glass micropipettes with a carbon fiber recording channel (0.3-1.0 M $\Omega$ ) were constructed using methods reported in Kyriazi et al. (1996). Briefly, a carbon fiber $(\sim 8 \mu \mathrm{m}$ diameter $)$ was inserted into a single barrel of an assembly of three glass capillary tubes (A-M Systems, Carlsburg, WA), and the assembly was pulled to a total tip diameter of $\sim 12 \mu \mathrm{m}$. The carbon fiber was then electrochemically etched to a conical tip and positioned within $20 \mu \mathrm{m}$ of the glass tip. Each of the two iontophoretic barrels was filled with either 100 mM NMDA (Sigma, St. Louis, MO) or $100 \mathrm{~mm}$ DL-2-amino-5-phosphonovaleric acid (APV; Sigma) in $0.9 \% \mathrm{NaCl}$, adjusted to $\mathrm{pH} 8.5$ with $0.2 \mathrm{~N} \mathrm{NaOH}$. These barrels had resistances of 30-60 M $\Omega$, and retaining currents of $+20 \mathrm{nA}$ were applied.

In our initial recordings we found that $\sim 10-20 \mathrm{nA}$ of current applied to the pipette containing NMDA was adequate to elevate spontaneous activities, and the same current levels simultaneously applied to the APV pipette reversed these effects. For cells included in our analysis of the effects of APV, we applied current levels sufficient to reduce SA to $50 \%$ of control values. In two cases, application of such current attenuated activity to 58 and $60 \%$ of control values, and these two cases are also included in our analysis. Applied currents to achieve these effects were $22 \pm 5 \mathrm{nA}$ (mean $\pm \mathrm{SD})$. For application of NMDA, current levels were increased until either evoked ON responses (see below) were reduced by $50 \%$ (before subtracting SA) or SA was increased by $>20$ spikes per second. The former was often a robust, reversible effect of NMDA application on RT neurons and was accompanied by only minimal increases in
SA (see Results). Mean currents for NMDA application on cells included in our analysis were $16 \pm 13 \mathrm{nA}$.

Whisker stimulation and data analysis. Hand-held probes were used to identify the whisker evoking the strongest response from an isolated unit, i.e., the principal whisker. A piezoelectric mechanical stimulator was then attached to this whisker $10 \mathrm{~mm}$ from the face (Simons, 1983). The stimulus consisted of a $1 \mathrm{~mm}$ ramp-and-hold deflection of the whisker from its resting position, with onset and offset velocities of $\sim 125 \mathrm{~mm} / \mathrm{sec}$ and a plateau duration of $200 \mathrm{msec}$. Individual trials were separated by 2 sec. Deflections were applied in each of eight randomly interleaved directions spanning $360^{\circ}$ in $45^{\circ}$ increments, and this was repeated 10 times for a total of 80 trials. Peristimulus time histograms (PSTHs) for each of the eight directions were computed and displayed on-line.

A time/amplitude window discriminator (BAK Electronics) and digital storage oscilloscope were used to isolate single units. Sequential spike event times were recorded with $100 \mu$ sec resolution on a DEC LSI 11/73. Subsequent data analysis was performed on an IBM PC using Microsoft Excel/Visual Basic and programs written with Interactive Data Language software (Research Systems, Inc., Boulder, CO). Statistical tests were performed using Microsoft Excel and the statistics package from SPSS, Inc. Two-tailed $t$ tests were used to compare distributions, and data are reported as means \pm SD unless noted otherwise.

Responses to whisker deflection onset (ON response) were computed as the mean number of spikes recorded over $40 \mathrm{msec}$ after deflection onset. Those recorded during NMDA or APV iontophoresis were corrected for different drug effects on SA levels by subtracting corresponding spontaneous firing rates. SA levels were determined by averaging spike counts over a $100 \mathrm{msec}$ period preceding the stimulus for all 80 trials. To assess changes in ON response timing, PSTHs were first constructed for each cell based on all 80 trials. A T50\% measure was then computed as the time of the 50th percentile spike in the PSTH over the appropriate response window.

Identification of burst and tonic firing modes. The analyses presented here are based on identification of SA preceding each whisker deflection trial as burst or tonic mode activity. Trials were considered burst mode if they exhibited either bursts or no SA and tonic mode if they exhibited single spike discharges. Remaining trials meeting none of these criteria were considered ambiguous. A burst was defined as the occurrence of six spikes within any $20 \mathrm{msec}$ period during the $150 \mathrm{msec}$ preceding the stimulus. These criteria, which are based on previous in vivo intracellular recordings (Mulle et al., 1986; Sumitomo et al., 1989), were chosen as a conservative means to identify spike bursts mediated by $I_{\mathrm{T}}$. Classification as single spike SA required that successive spikes in the $150 \mathrm{msec}$ prestimulus period never occurred with an interspike interval (ISI) $<7 \mathrm{msec}$ (i.e., instantaneous firing rate did not exceed 143 spikes per second). Data were also analyzed using longer minimum ISIs for identification of single spike trials, and results obtained were similar to those reported here.

\section{Results}

We recorded activities of 114 RT neurons in a total of 17 animals. Data from 85 of these neurons obtained in 9 animals have been analyzed previously using PSTHs and other trial-averaging techniques and have been published previously (Hartings et al., 2000). Here we apply different analyses to this control data set to investigate detailed firing patterns of individual whisker-evoked responses and their dependence on immediately preceding SA. In microiontophoresis experiments an additional 29 neurons were recorded in 6 animals.

\section{Spontaneous firing modes}

The raster plots for six different neurons in Figure 1 show representative spontaneous and whisker-evoked spike patterns observed in RT. There is considerable heterogeneity in firing patterns both among cells and among trials for individual cells. Much variability is attributable to whether neurons fire in burst or tonic mode. In tonic mode (Fig. $1 A, B$ ), cells discharge single spikes with equal probability at each point in time. In burst mode, 
cells exhibit grouped discharges separated by periods of quiescence (Fig. 1C). Some cells remained in either tonic (Fig. $1 A, B$ ) or burst mode (Fig. 1C) throughout the duration of the recording. Others fluctuated between modes over the time course ( $\sim 3 \mathrm{~min}$ ) of a battery of stimulus trials (Fig. $1 D$ ) or exhibited activity that could not be easily classified (Fig. $1 D-F$ ).

Although definitive classification of burst versus tonic mode firing requires intracellular recordings, we used spike patterns in the $150 \mathrm{msec}$ period preceding the stimulus to separate individual trials according to SA patterns that are characteristic of burst or tonic firing modes (see Materials and Methods). Units were in burst mode for $48 \%$ of all trials, consisting of $40 \%$ with no SA and $8 \%$ with spontaneous bursts. Identified spontaneous bursts exhibited a clear accelerando-decelerando pattern, with the first through third ISIs progressively shorter and fourth through sixth progressively longer (Fig. $3 C)(p<0.001)$. Tonic single spike activity constituted $32 \%$ of trials, and the remaining 20\% did not meet criteria for either mode and were considered ambiguous.

\section{Sensory responses}

As shown in the raster plots of Figure 1, neurons were responsive to whisker deflections regardless of their firing mode. To determine whether firing mode influences the temporal structure of these responses, we accumulated separate $\mathrm{ON}$ response PSTHs for trials with different SA patterns. When cells were quiescent, population $\mathrm{ON}$ responses consisted of a slow $\sim 15 \mathrm{msec}$ rise to the peak firing rate followed by a slow $\sim 20$ msec decay (Fig. $2 A)$. Responses averaged 6.22 ( \pm 4.41$)$ spikes per stimulus. Within evoked spike trains, ISIs followed an accelerando-decelerando pattern: initial ISIs (one to three) became progressively shorter and subsequent ISIs (four to six) became longer (Fig. 3A,C) $(p<0.001$ for first vs second, fourth vs fifth). Such accelerando-decelerando response patterns were also observed in individual trials (Fig. $4 A, B)$, which could reach peak firing rates of $>500$ spikes per second and consist of up to 15 spikes per stimulus. The similarity of these evoked responses to spontaneously occurring bursts suggests that they reflect $I_{\mathrm{T}}$-mediated events (Fig. $3 C$ ).

Responses preceded by spontaneous bursts had temporal patterns (Fig. $2 B$ ) and spike counts (6.28 \pm 3.33 spikes per stimulus) similar to those preceded by quiescence, with the exception that the rise and peak of the population response occurred slightly earlier. When spontaneous bursts were followed by quiescence, cells discharged whisker-evoked bursts (Fig. 4C,D) provided that
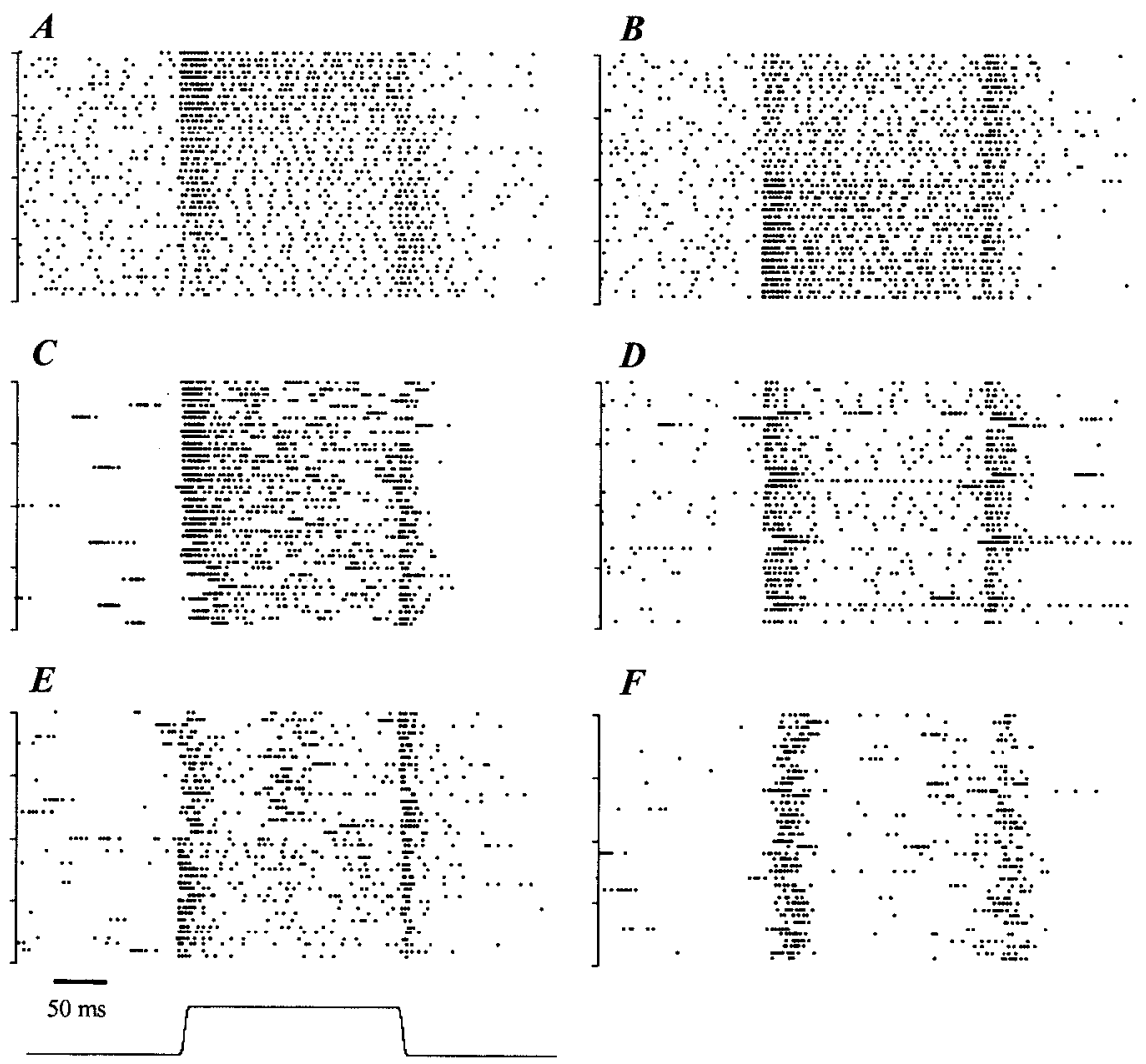

Figure 1. Heterogeneity of spontaneous and stimulus-evoked spike patterns in RT. $A-F$, Raster plots of single-unit responses; each panel shows a separate unit. For each unit 10 trials $X$ four directions spanning $135^{\circ}$ in $45^{\circ}$ increments are shown; trials at each of the four directions are separated by tick marks. The total duration is $500 \mathrm{msec}$, and the stimulus waveform is shown below.
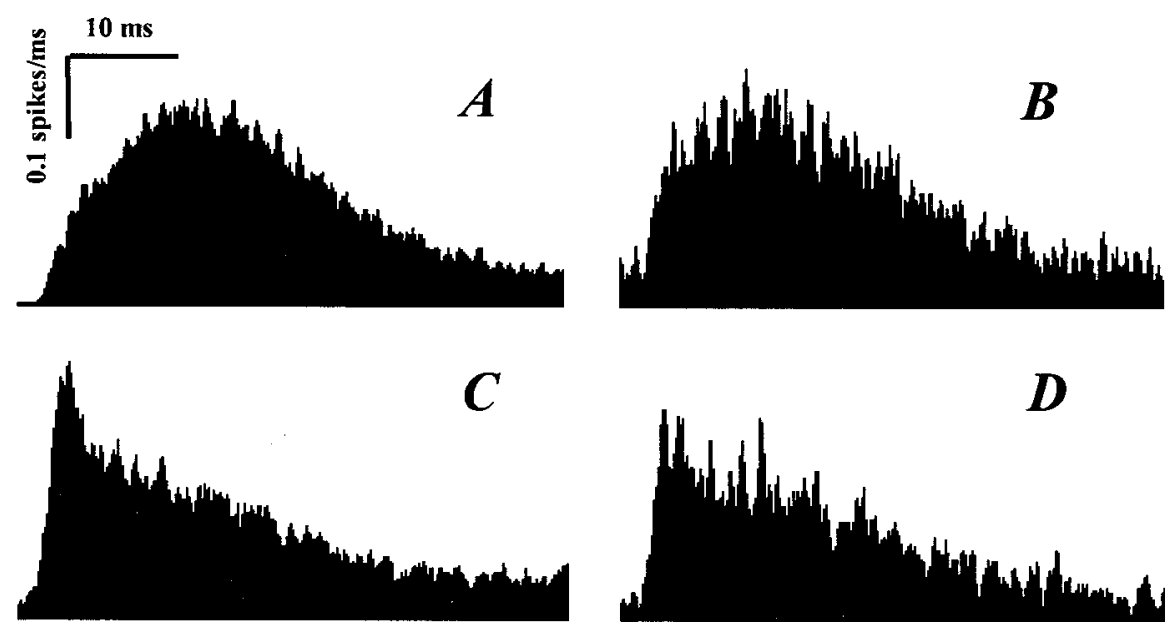

Figure 2. State-dependent population responses. Evoked response PSTHs were accumulated by separation of responses on a trial-by-trial basis according to classification of SA occurring $150 \mathrm{msec}$ before the stimulus. A, No SA. B, Grouped discharge. C, Two or more single spikes. D, One spike.

the deflections occurred $>20$ msec after the spontaneous burst. These responses were larger when bursts began 100-150 msec $(6.74 \pm 3.83$ spikes per stimulus) or $50-100 \mathrm{msec}(6.76 \pm 3.63$ spikes per stimulus) before deflections, compared with when they began within 50 msec of whisker deflection (5.24 \pm 2.77 spikes per stimulus; $p<0.001$ ). On some trials, spontaneous bursts were followed by tonic discharge both spontaneously and in response to whisker deflections. This occurred with greater probability when whisker deflection more immediately followed burst 

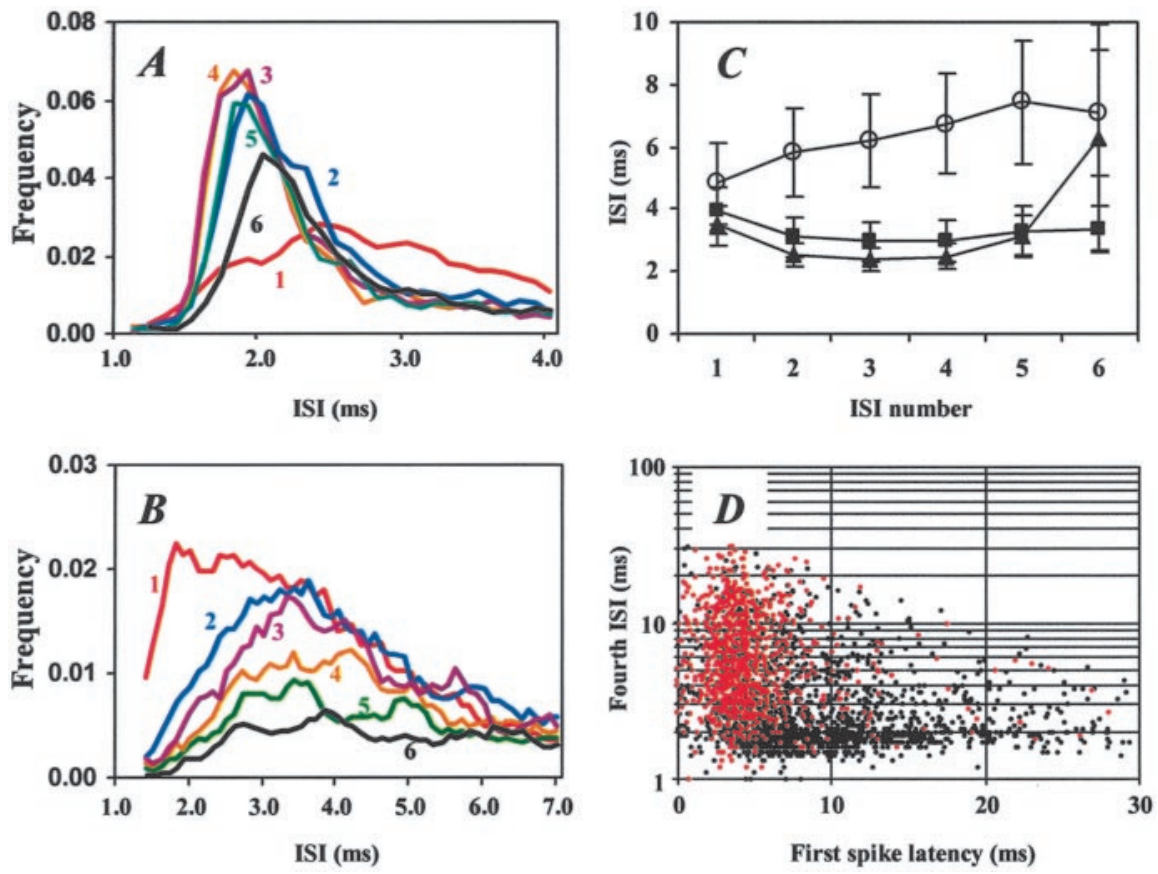

Figure 3. ISI patterns of evoked responses. $A, B$, Distributions of ISI values for consecutive ISIs numbers (1-6) occurring after stimulus onset. $A$ and $B$ were accumulated separately for responses after quiescent (Fig. 2A) and single spike (Fig. 2B) SA, respectively. The ordinate axes represent frequency (number of ISIs/100 $\mu \mathrm{sec}$ bin/number of trials) and are shown on different scales. The abscissa in $A$ has an expanded scale to show differences between its distribution curves. C, Mean ISI values ( \pm SEM) after quiescent $(\square)$ and single spike $(O)$ SA. For each ISI number, values were significantly different between the two conditions ( $p<$ 0.001). ISIs accumulated for all spontaneously occurring bursts $(\boldsymbol{\Delta})$ are shown for comparison. $D$, First spike latencies are plotted versus fourth ISI values for all quiescent (black) and single spike (red) SA trials.

discharge (e.g., $<50 \mathrm{msec}$ ), and this tonic activity accounts for the more rapid rise in the population response (Fig. $2 \mathrm{~B}$ ).

Responses evoked after single spike (i.e., tonic) SA had a markedly different temporal structure than those after quiescence or burst discharge. For instance, when even only one spike occurred in the $150 \mathrm{msec}$ prestimulus period, responses exhibited a rapid $1.5 \mathrm{msec}$ rise to peak firing rate followed by a $\sim 35 \mathrm{msec}$ decay and averaged 4.54 ( \pm 2.68$)$ spikes per stimulus (Fig. 2D). Responses after higher rates of single spike activity ( $\geq 2$ spikes/ $150 \mathrm{msec}$ ) exhibited the same temporal structure but were somewhat larger in magnitude $(5.23 \pm 2.59$ spikes per stimulus) (Fig. 2C).

Initial ISIs after single spike activity were shortest, and subsequent ISIs grew progressively longer (Fig. $3 B, C)(p<0.05$ for first vs second, third vs fourth, fourth vs fifth), indicating that peak instantaneous firing rates were usually achieved immediately in the response. Initial ISIs were shorter than second ISIs on $60 \%$ of individual trials, in contrast to trials after quiescent SA $\left(35 \% ; \chi^{2}, p<0.001\right)$. In addition, for each ISI number, ISI values were longer after single spike than quiescent SA (Fig. 3) $(p<$ $0.001)$. Some cells, particularly those with high rates of single spike spontaneous discharge (Fig. $1 A, B$ ), maintained firing rates of 300-400 spikes per second through several consecutive spikes and discharged up to 12 spikes per stimulus (Fig. $4 E, F$ ). Thus, despite subtle yet robust differences in temporal structure, responses evoked after different SA patterns are of the same total duration and could consist of nearly equivalent high spike counts.

Examination of raster plots suggests that evoked discharges after single spike SA occur earliest and with the least spike timing variability. Indeed, under this condition, initial evoked spikes are more time-locked to the stimulus than those evoked after quiescence (Fig. 4G) $(p<0.001)$. The narrower distribution for single spike responses indicates greater fidelity, or population synchrony, in first spike timing. To determine how well population differences in evoked spike timing and frequency can distinguish SA patterns preceding individual responses, first spike times were plotted versus fourth ISI values for quiescent and single spike SA trials (Fig. 3D). A line through this plane separated trials with 76 and $79 \%$ accuracy for the two SA states $\left(\chi^{2}, p<0.001\right)$. Interestingly, a shift between the two evoked spike patterns (i.e., after quiescence vs single spike activity) could be effected by previous whisker deflections (Fig. 4H). In Figure $4 H$, the latencies of responses to deflection onsets and offsets are longer and more variable when preceded by quiescence, in contrast to the OFF responses after tonic discharge.

\section{Effects of APV microiontophoresis}

Synaptic depolarizations mediated by NMDA receptors have longer durations than those mediated by AMPA/kainate receptors. The long duration of RT responses after tonic activity, when $I_{\mathrm{T}}$ channels are likely inactivated, thus suggested that NMDA currents may contribute prominently to the stimulus-evoked responses observed in our recordings. To test this we recorded RT unit activity through multibarrel glass pipettes while microiontophoretically applying the selective NMDA receptor antagonist APV. APV reduced spontaneous activities from $21.5( \pm 15.6)$ to $7.6( \pm 6.7)$ spikes per second but reduced evoked ON responses only from $3.8( \pm 1.8)$ to 3.2 ( \pm 2.0 ) spikes per stimulus (Fig. 5). Response duration was not appreciably affected. Thus, activation of NMDA receptors is not likely the principal mechanism mediating the RT response.

\section{Effects of NMDA microiontophoresis}

To test the pharmacological specificity of the effects of APV and ensure that the applied drug was accessing NMDA receptors, for several cells we applied NMDA alone and in combination with APV. Although APV application reversed changes induced by NMDA (data not shown), we found that iontophoresis of NMDA alone altered RT activity in an unexpected manner. Figure 6 illustrates these changes for two cells showing robust effects. Under control conditions, both cells discharged to deflection onsets and offsets with a large number of spikes. When their spontaneous activities were increased as a result of NMDA application, however, sensory responses to whisker deflections were virtually abolished. Responses fully recovered when retaining currents were again applied and spontaneous activities returned to control levels.

Mean effects of NMDA on 14 neurons are shown in PSTHs in Figure $7 A$. Although NMDA application induced a mean increase in spontaneous activities of 35 spikes per second (286\% of control), evoked ON responses were reduced to $61 \%$ of control values $(4.9 \pm 2.6$ vs $2.2 \pm 1.7$ spikes per stimulus; $p<0.01)$. PSTHs also show a change in the temporal profile of the $\mathrm{ON}$ response 
Quiescent S.A.

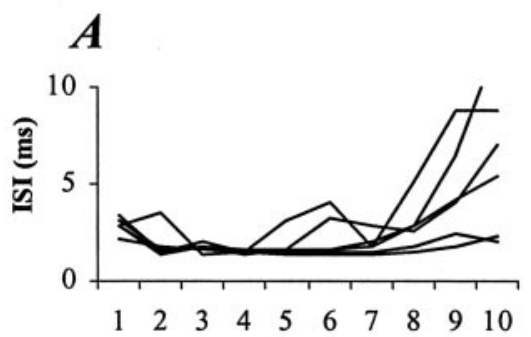

ISI number



150

ms

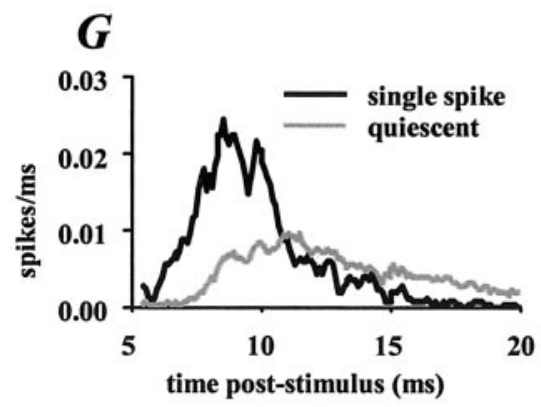

Grouped Discharge S.A.

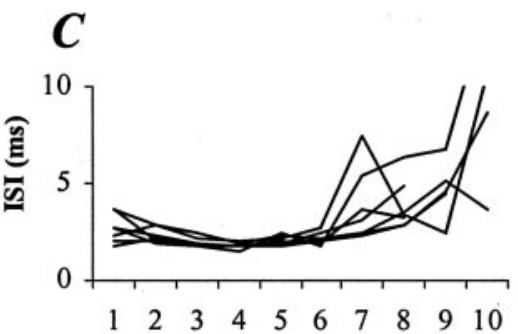

ISI number

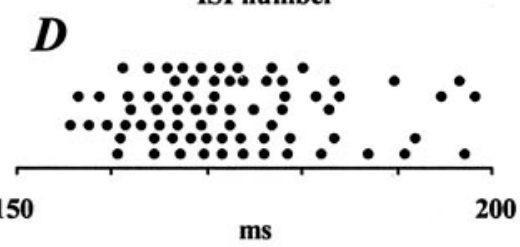

200
Single Spike S.A.

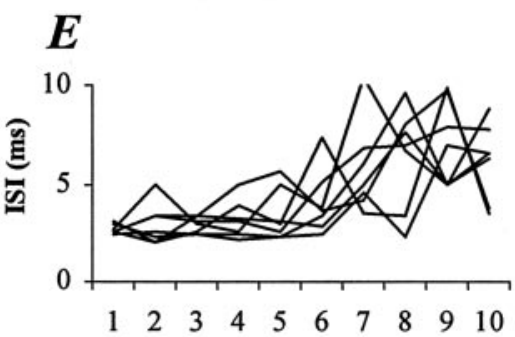

ISI number

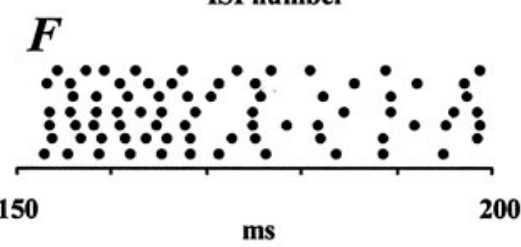

200

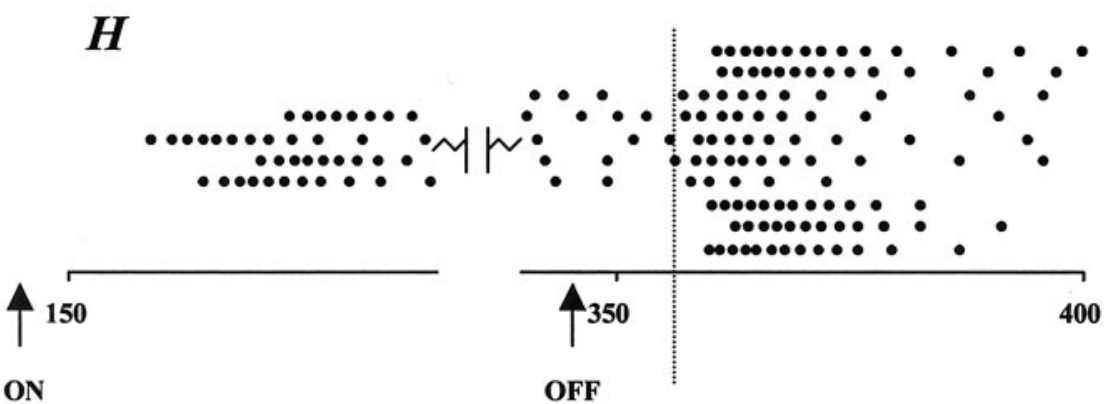

Figure 4. State-dependent single-unit responses. $A, C, E$, The first 10 consecutive $I S I$ values after stimulus onset for trials with no $S A(A)$, grouped discharge $S A(C)$, and more than or equal to five single spikes (E). Each graph shows seven trials from a separate unit. $B, D, F$, The same data as in $A, C$, and $E$, respectively, plotted in raster format. G, PSTHs were accumulated on the basis of the timing of the first spike only for all trials with no SA (gray) and all trials with single spike $S A$ (black). $H$, Raster plots of $O N$ and $0 F F$ responses of a unit to 10 whisker deflection trials at the same deflection angle. The dotted line is placed to facilitate comparison of OFF response latencies when preceded by tonic versus no activity. No activity preceded the $0 \mathrm{~N}$ response on any trial.

similar to differences between those in tonic and burst mode (Fig. 2). Under control conditions $24 \%$ of all trials met criteria for single spike SA and 53\% had no SA, but these proportions shifted to 32 and $3 \%$, respectively, during NMDA application $\left(\chi^{2}, p<\right.$ $0.01)$. Thus, because responses evoked during burst mode are larger than those evoked during tonic activity (see above), some reduction in response magnitude can be attributed to the depolarizing effect of NMDA and its induction of SA in the recorded neuron.

Reduction of evoked responses during application of NMDA varied somewhat from cell to cell. We hypothesized that this variability was caused by different degrees of depolarization induced by NMDA in the recorded cells. However, we found that cells with the greatest increase in SA exhibited the least reduction in $\mathrm{ON}$ response magnitude (Fig. 7B) $\left(r^{2}=0.71 ; p<0.01\right)$. Rather, reduction in the $\mathrm{ON}$ response was positively correlated with the amount of iontophoretic current applied to the recorded cell (Fig. 7C) $\left(r^{2}=0.58 ; p<0.01\right)$.

\section{Discussion}

The burst and tonic firing modes of RT neurons are defined by different patterns of spontaneous spike discharge. Here we investigated the influence of these activity modes on sensory responses by separately analyzing trials preceded by quiescence or burst discharge, corresponding to burst mode, from those preceded by single spike discharge, corresponding to tonic mode. We found that whisker-evoked responses in both burst and tonic mode consisted of characteristic large spike counts and long durations.
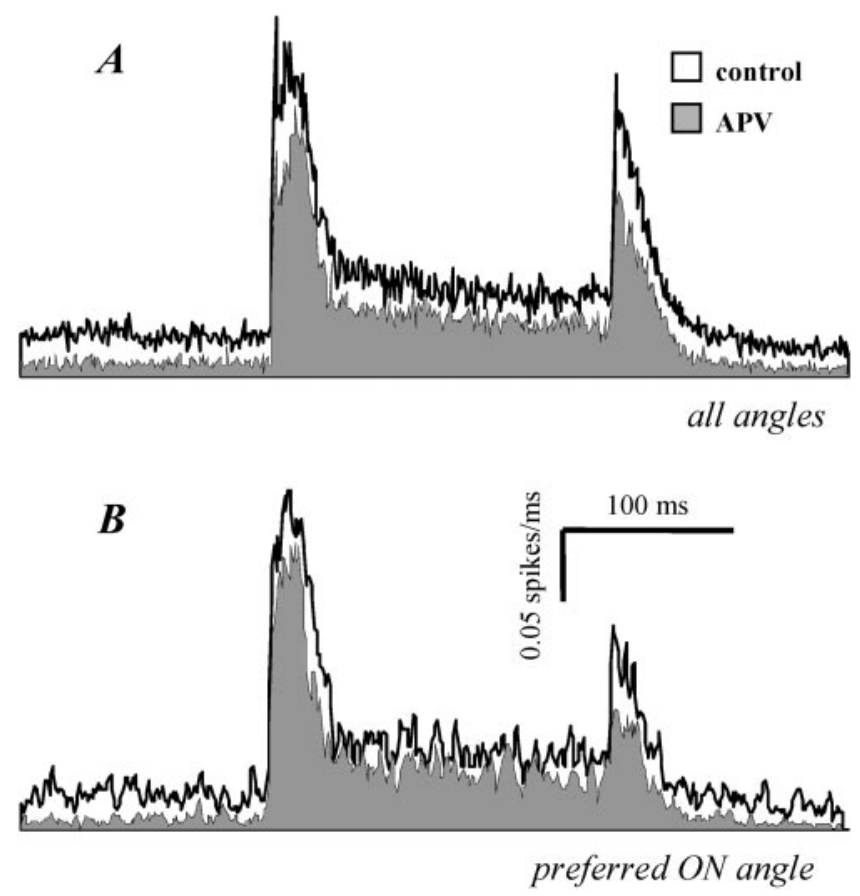

Figure 5. Mean effects of APV on RT activity. A, PSTHs accumulated over 22 units and all deflection angles, under control conditions (open histogram) and during APV application (filled histogram). B, PSTHs for all 22 units at directions evoking their maximal ON responses. 


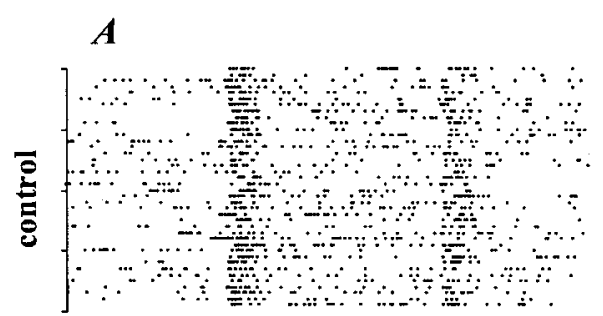

\section{$\boldsymbol{B}$}
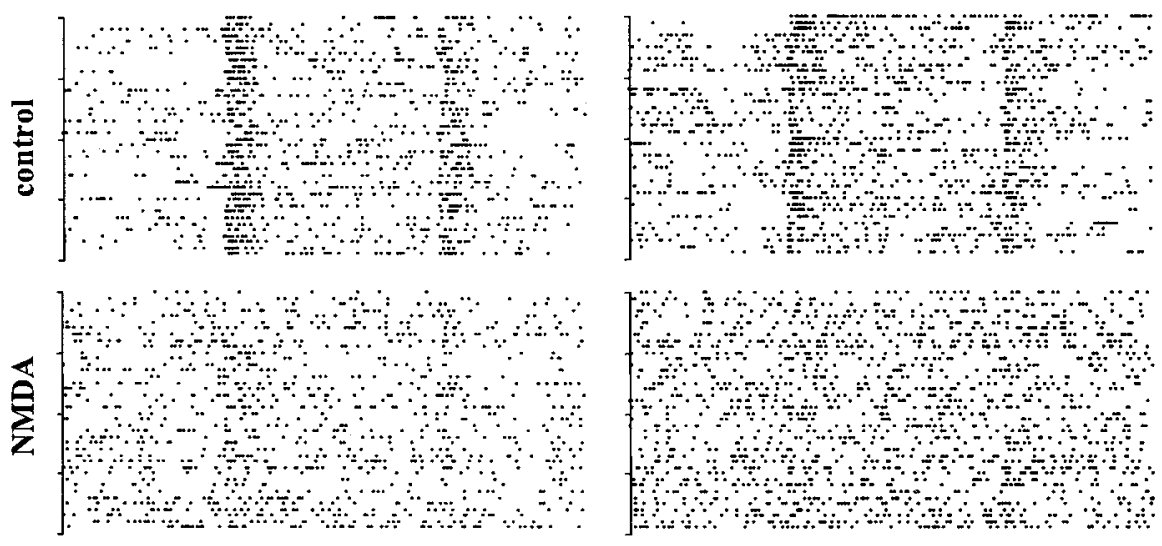

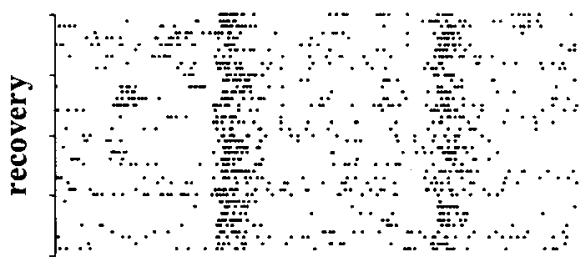

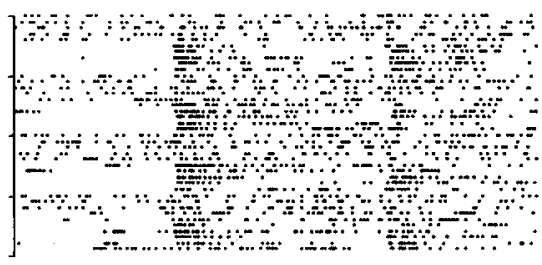

$50 \mathrm{~ms}$

Figure 6. Effects of NMDA on single-unit responses. $A, B$, Responses of two single units to 40 stimulus trials under control conditions, during NMDA iontophoresis, and after recovery. Conventions are the same as in Figure 1.

Thus, the high responsiveness of RT neurons reflects not only burst generation, but also the postsynaptic amplification of brief but synchronous inputs from thalamocortical neurons (Hartings et al., 2000).

The temporal structure of evoked responses differed when whiskers were deflected during tonic versus burst mode activity; only the latter condition was associated with accelerando-decelerando firing in the evoked response. Remarkably, the presence of only a single spike in $150 \mathrm{msec}$ preceding the stimulus was sufficient to identify tonic mode and predict the corresponding response pattern. These results validate the criteria used for identification of burst and tonic mode SA and suggest that different synaptic-evoked currents are used by RT neurons for sensory processing according to state-related strategies.

\section{Temporal profiles of sensory responses in tonic and burst modes}

Although sensory responses evoked during burst and tonic mode have similar overall durations, they differ in their temporal profiles. When deflections are delivered during tonic mode activity, population responses show a rapidly rising early component that is likely mediated by AMPA receptors. This early component reflects short response latencies, low variability of first spike timing, and peak instantaneous firing rates. In contrast, population responses evoked during burst mode activity exhibit a slow rise, attributable to both an initial accelerando pattern of ISIs and the variability and long latency of first spike timing. In burst mode the presumed hyperpolarized state of the cells would likely preclude short latency spiking resulting directly from AMPAmediated EPSPs. Rather, $I_{\mathrm{T}}$-mediated LTS bursts with accelerando-decelerando spike patterns are likely triggered by initial subthreshold AMPA currents.

\section{Mechanisms of long duration tonic responses}

During burst mode activity, whisker-evoked responses consisted of up to 15 spikes per stimulus, with instantaneous firing rates exceeding 500 spikes per second, and averaged 6.22 spikes per stimulus. Responses evoked during tonic activity consisted of similar high firing rates and long durations (5.23 spikes per stimulus) (compare Fig. 1, $A$ and $C$, with Fig. $2 A, C$ $E)$. Because thalamocortical neurons fire only 1.27 spikes per whisker deflection (Hartings et al., 2000), RT responses during tonic mode reflect an amplification mechanism independent of $I_{\mathrm{T}}$ channels, which are presumably inactivated during this state. Responses are also unlikely to depend substantially on NMDA receptors (Liu, 1997; Jones et al., 1998), because antagonizing them produced only minimal effects on response magnitudes.

A possible contributor to the large magnitude of tonic RT responses, compared with those of thalamocortical neurons, is a high degree of convergence of relay cells onto RT neurons. Although there are an estimated 250-300 thalamocortical cells with the same receptive field center (i.e., principal whisker) (Land et al., 1995), there are only 10-30 corresponding RT cells (Shosaku, 1986). Because $80 \%$ of thalamocortical cells show physiological connections with RT (Shosaku, 1986), these numbers likely reflect a high convergence ratio. Another factor contributing to large response magnitudes may be a low level of intra-RT inhibition. Zhang et al. (1997) found that monosynaptic IPSPs in RT neurons were approximately four times smaller than those recorded in thalamocortical neurons. The extensive ramifications of RT axons in relay nuclei, as compared with the sparse collateralization within RT, may underlie this difference (Yen et al., 1985; Pinault et al., 1995; Cox et al., 1996).

A third candidate mechanism for response amplification is electrical coupling, whereby RT neurons can potentiate firing in neighboring cells (Landisman et al., 2002). Effects of such coupling were shown to be strongest when presynaptic neurons fire bursts and postsynaptic cells are depolarized, close to firing threshold. Thus it is possible that electrical coupling among RT neurons allows whisker-evoked bursts generated in some neurons to contribute to depolarization in neighboring neurons. The transfer of LTS potentials from neighboring cells could contribute to the long duration and high spike counts of postsynaptic cells firing in tonic mode, if nearby RT cells are active simultaneously in different firing modes; this remains to be investigated. Finally, high input resistances of RT neurons may further contribute to large PSP amplitudes (McCormick and Prince, 1986).

\section{Effects of NMDA receptor antagonism}

A gap junction mechanism for the amplification of sensory responses may also explain why NMDA application reduced and in some cases abolished responses to whisker deflections. The magnitude of the effect of NMDA on the ON responses of cells correlated with the amplitude of iontophoretic current applied. If it is assumed that the magnitude of applied current is proportional to the spatial extent of the drug's spread, then NMDA may have acted on the recorded neuron through its effects on the local neuronal population. Through its depolarizing effect, larger current applications may have inactivated $I_{\mathrm{T}}$ in the local neuron 
$A$

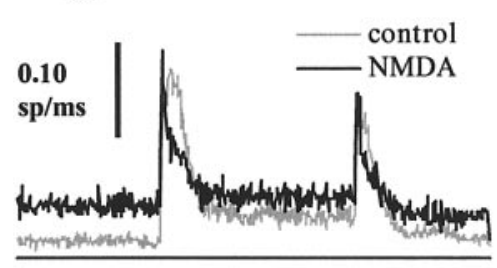

$100 \mathrm{~ms}$
$\boldsymbol{B}$

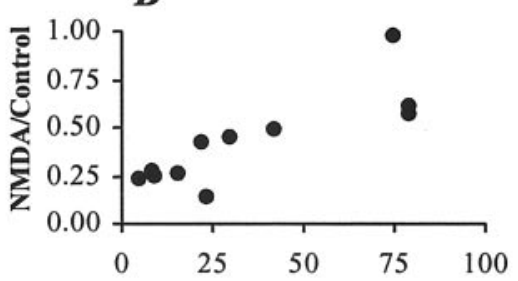

Increase in Spontaneous Activity



Applied Current (nA)

Figure 7. Mean effects of NMDA on RT responses. A, PSTHs were accumulated over 12 units and all deflection angles, under control conditions and during NMDA microiontophoresis. Reductions in $0 \mathrm{~N}$ responses (NMDA response divided by control response) are shown as a function of the NMDA-induced increase in the recorded unit's $S A(B)$, and the amplitude of iontophoretic current applied (C). Each symbol represents a single unit.

population, resulting in responses (Fig. 7A) more similar to those in tonic firing mode (Fig. 2). The responses of some cells, such as those shown in Figure 5, may be especially dependent on $I_{\mathrm{T}}$, either generated in the recorded neurons themselves or communicated to them through coupling to other cells.

Other explanations for the effects of NMDA are possible but less likely. Reductions in evoked spike counts cannot be attributed to saturation of receptors by exogenously applied NMDA, because neurons showing the greatest increases in SA were those with the least reduction in evoked responses. Also, on the basis of removal of $\mathrm{Mg}^{2+}$ block, presumed depolarization by NMDA would be expected to facilitate rather than saturate responses. Because the same current polarity and amplitudes produced different effects when used to apply APV, effects cannot be attributed to the iontophoretic current itself. Finally, it remains possible that NMDA acts on RT neurons to reduce evoked excitability via an unknown mechanism that is independent of its effects on SA.

\section{Role of RT in state-dependent sensory processing}

Previous investigations of sensory gating and relay in the thalamus have focused on cellular properties of thalamocortical neurons (Sherman and Guillery, 1996), particularly on the significance of burst and tonic mode activities. Both firing modes are observed during wakeful activity and are influenced by stimulus parameters as well as an animal's level of vigilance (Guido and Weyand, 1995; Ramcharan et al., 2000; Weyand et al., 2001). It is thus suggested that the firing modes reflect distinct sensory processing functions, including different strategies for encoding information (Reinagel et al., 1999).

RT neurons, which are strategically positioned to modify information transfer bidirectionally between thalamus and cortex, also transition between burst and tonic firing modes during wakefulness, depending on an animal's state of vigilance (Mukhametov et al., 1970; Steriade et al., 1986). Because RT neurons are responsive to sensory stimulation in both modes, as demonstrated here, burst and tonic firing in RT are also likely to have distinct consequences for state-dependent processing in the thalamocortical loop. In particular, during periods of relative quiescence, a more slowly developing RT response (Fig. 2A), mediated by $I_{\mathrm{T}}$ in burst mode, would allow a strong signal to be relayed by thalamocortical neurons and serve as a "wake-up" call to cortex. During higher rates of tonic firing, as occur during attentive behavior, a rapidly developing RT response (Fig. $2 \mathrm{~B}$ ) would provide an immediate but briefer inhibition appropriate for faithful thalamocortical signaling of rapid, subtle changes in peripheral stimuli. Indeed, GABAergic inhibition can affect evoked firing patterns of thalamocortical neurons within $5 \mathrm{msec}$ of the response (Hartings and Simons, 2000). Because cortical layer IV circuits are particularly sensitive to thalamocortical activity within this time window ( $\sim 7 \mathrm{msec}$ ) (Pinto et al., 2003), the differences in first spike latency and synchrony in RT during tonic versus burst firing may be particularly consequential.

The time course of excitation and inhibition in thalamocortical neurons has been shown to vary depending on an animal's behavioral and vigilant state in a manner consistent with RT firing patterns observed here (Fanselow and Nicolelis, 1999). When animals engage in exploratory motor behaviors, including active whisking, thalamocortical responses are brief, consistent with tonic RT firing, and are followed by short ( $\sim 25 \mathrm{msec})$ periods of inhibition. During periods of wakeful inactivity, however, responses are more prolonged and followed by extended periods of reduced excitability, consistent with burst RT firing.

In a broader context, our results are consistent with previous and continuing studies that have shown RT neurons to be activated in a sensory-specific manner during wakeful behaviors. Yen et al. (1999) reported firing that was phase-locked to whisker twitching, and we have observed enhanced multiunit activity during both passive whisker stimulation and active exploratory whisker movements (our unpublished observations). Indeed, RT activities are elevated during behaviorally relevant tasks (Montero, 1997) and may mediate attentional processes (Weese et al., 1999). It will be important in future studies to combine these awake, behaving paradigms with analysis of single-unit firing modes to more definitively determine the role of RT role in state-dependent sensory processing.

\section{References}

Contreras D, Dossi RC, Steriade M (1993) Electrophysiological properties of cat reticular thalamic neurones in vivo. J Physiol (Lond) 470:273-294.

Cox CL, Huguenard JR, Prince DA (1996) Heterogeneous axonal arborizations of rat thalamic reticular neurons in the ventrobasal nucleus. J Comp Neurol 366:416-430.

Crick F (1984) Function of the thalamic reticular complex: the searchlight hypothesis. Proc Natl Acad Sci USA 81:4586-4590.

Domich L, Oakson G, Steriade M (1986) Thalamic burst patterns in the naturally sleeping cat: a comparison between cortically projecting and reticularis neurons. J Physiol (Lond) 379:429-449.

Dworkin BR, Dworkin S (1995) Learning of physiological responses: II. Classical conditioning of the baroreflex. Behav Neurosci 109:1119-1136.

Fanselow EE, Nicolelis MAL (1999) Behavioral modulation of tactile responses in the rat somatosensory system. J Neurosci 19:7603-7616.

Guido W, Weyand T (1995) Burst responses in thalamic relay cells of the awake behaving cat. J Neurophysiol 74:1782-1786.

Harkness JE, Wagner JE (1989) The biology and medicine of rabbits and rodents. Philadelphia: Lea \& Febiger. 
Hartings JA, Simons DJ (2000) Inhibition suppresses transmission of tonic vibrissa-evoked activity in the rat ventrobasal thalamus. J Neurosci 20:RC100(1-5).

Hartings JA, Temereanca S, Simons DJ (2000) High responsiveness and direction sensitivity of neurons in the thalamic reticular nucleus of the rat to whisker deflections. J Neurophysiol 83:2791-2801.

Huguenard JR, Prince DA (1992) A novel T-type current underlies prolonged $\mathrm{Ca}^{2+}$-dependent burst firing in GABAergic neurons of rat thalamic reticular nucleus. J Neurophysiol 12:3804-3817.

Jones EG, Tighilet B, Tran B-V, Huntsman MM (1998) Nucleus- and cellspecific expression of NMDA and non-NMDA receptor subunits in monkey thalamus. J Comp Neurol 397:371-393.

Kyriazi HT, Carvell GE, Brumberg JC, Simons DJ (1996) Quantitative effects of GABA and bicuculline methiodide on receptive field properties of neurons in real and simulated whisker barrels. J Neurophysiol 75:547-560.

Land PW, Buffer SA, Yaskosky JD (1995) Barreloids in adult rat thalamus: three-dimensional architecture and relationship to somatosensory cortical barrels. J Comp Neurol 355:573-588.

Landisman CE, Long MA, Beierlein M, Deans MR, Paul DL, Connors BW (2002) Electrical synapses in the thalamic reticular nucleus. J Neurosci 22:1002-1009.

Liu X-B (1997) Subcellular distribution of AMPA and NMDA receptor subunit immunoreactivity in ventral posterior and reticular nuclei of rat and cat thalamus. J Comp Neurol 388:587-602.

McCormick DA, Prince DA (1986) Acetylcholine induces burst firing in thalamic reticular neurones by activating a potassium conductance. $\mathrm{Na}$ ture 319:402-405.

Montero VM (1997) C-fos induction in sensory pathways of rats exploring a novel complex environment: shifts of active thalamic reticular sectors by predominant sensory cues. Neuroscience 76:1069-1081.

Mukhametov LM, Rizzolatti G, Tradardi V (1970) Spontaneous activity of neurones of nucleus reticularis thalami in freely moving cats. J Physiol (Lond) 210:651-667.

Mulle C, Madariaga A, Deschenes M (1986) Morphology and elecrophysiological properties of reticularis thalami neurons in cat: in vivo study of a thalamic pacemaker. J Neurosci 6:134-145.

Nicolelis MA, Fanselow EE (2002) Thalamocortical optimization of tactile processing according to behavioral state. Nat Neurosci 5:517-523.

Paxinos G, Watson C (1982) The rat brain in stereotaxic coordinates. New York: Academic.

Pinault D, Deschenes M (1998) Projection and innervation patterns of individual thalamic reticular axons in the thalamus of the adult rat: a threedimensional, graphic, and morphometric analysis. J Comp Neurol 391: $180-203$.

Pinault D, Bourassa J, Deschenes M (1995) The axonal arborization of single thalamic reticular neurons in the somatosensory thalamus of the rat. Eur J Neurosci 7:31-40.

Pinto DJ, Hartings JA, Brumberg JC, Simons DJ (2003) Cortical damping: analysis of thalamocortical response transformations in rodent barrel cortex. Cereb Cortex 13:33-44.
Pollin B, Rokyta R (1982) Somatotopic organization of nucleus reticularis thalami in chronic awake cats and monkeys. Brain Res 250:211-221.

Ramcharan EJ, Gnadt JW, Sherman SM (2000) Burst and tonic firing in thalamic cells of unanesthetized, behaving monkeys. Vis Neurosci 17:55-62.

Reinagel P, Godwin D, Sherman SM, Koch C (1999) Encoding of visual information by LGN bursts. J Neurophysiol 81:2558-2569.

Scheibel ME, Scheibel AB (1966) The organization of the nucleus reticularis thalami: a Golgi study. Brain Res 1:43-62.

Sherman SM, Guillery RW (1996) Functional organization of thalamocortical relays. J Neurophysiol 76:1367-1395.

Shosaku A (1985) A comparison of receptive field properties of vibrissa neurons between the rat thalamic reticular and ventro-basal nuclei. Brain Res 347:36-40.

Shosaku A (1986) Cross-correlation analysis of a recurrent inhibitory circuit in the rat thalamus. J Neurophysiol 55:1030-1043.

Shosaku A, Kayama Y, Sumitomo I (1984) Somatotopic organization in the rat thalamic reticular nucleus. Brain Res 311:57-63.

Simons DJ (1983) Multi-whisker stimulation and its effects on vibrissa units in rat SmI barrel cortex. Brain Res 276:178-182.

Simons DJ, Carvell GE (1989) Thalamocortical response transformation in the rat vibrissa/barrel system. J Neurophysiol 61:311-330.

Spreafico R, de Curtis M, Frassoni C, Avanzini G (1988) Electrophysiolog ical characteristics of morphologically identified reticular thalamic neurons from rat slices. Neuroscience 27:629-638.

Steriade M, Domich L, Oakson G (1986) Reticularis thalami neurons revisited: activity changes during shifts in states of vigilance. J Neurosci 6:68-81

Sumitomo I, Iwama K (1987) Neuronal organization of rat thalamus for processing information of vibrissal movements. Brain Res 415:389-392.

Sumitomo I, Takahashi Y, Kayama Y, Ogawa T (1989) Burst discharges of thalamic reticular neurons: an intracellular analysis in anesthetized rats. Brain Res 482:34-41.

Weese GD, Phillips JM, Brown VJ (1999) Attentional orienting is impaired by unilateral lesions of the thalamic reticular nucleus in the rat. J Neurosci 19:10135-10139.

Weyand TG, Boudreaux M, Guido W (2001) Burst and tonic response modes in thalamic neurons during sleep and wakefulness. J Neurophysiol 85:1107-1118.

Yen C-T, Conley M, Hendry SH, Jones EG (1985) The morphology of physiologically identified GABAergic neurons in the somatic sensory part of the thalamic reticular nucleus in the cat. J Neurosci 5:2254-2268.

Yen C-T, Shaw F-Z, Chapin JK (1999) Ensemble recording of somatosensory reticular thalamic neurons in awake and behaving rats. Soc Neurosci Abstr 2:2197.

Zhang SJ, Huguenard JR, Prince DA (1997) GABA $_{\mathrm{A}}$ receptor-mediated $\mathrm{Cl}$ currents in rat thalamic reticular and relay neurons. J Neurophysiol 78: $2280-2286$ 